\title{
Digitalization in management of fishery integration associations
}

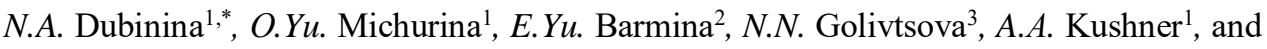 \\ M.A. Kushner ${ }^{1}$ \\ ${ }^{1}$ Astrakhan State Technical University, 16 Tatisheva St, Astrakhan, 414025, Russia \\ ${ }^{2}$ Saint Petersburg State University of Economics, 21 Sadovaya St, St Petersburg, 191023, Russia \\ ${ }^{3}$ Saint-Petersburg State University of Industrial Technologies and Design, Russia, 18 Bolshaya \\ Morskaya St, St Petersburg, 191186, Russia
}

\begin{abstract}
The paper represents a method for the digitalization in management by creating a Unified Management Information System, which provides an opportunity to analyze the data and expedite the decisionmaking process, to fulfill strategic objectives, maintain and enhance competitive advantages of fishery integration associations. The study proposes a concept of UMIS structure adjusted for the activity peculiarities of integration association member companies, which facilitates greater efficiency of interactions and communication between them. The designed organizational structure, concentrated on the key activities of integration association and built on the principles of centralization, which allows for a creation of a single business model of member companies, serves as a basis for the UIMS implementation.
\end{abstract}

\section{Introduction}

Information technology (IT) amidst the global economy digitalization has now become a key component for the effective management of various forms of business associations in all economic sectors. IT is considered as a project form of expression of theory and practice, which allows to organize the activities more effectively. The purpose of modern technologies is not only to help people to search for and automate time-taking and repetitive processes, but also acquire new data on operations of business entities for a rational decision making to improve their activities. And the fishery is no exception here.

Since the fishery sector is a system of completely interconnected industrial and business elements, i.e. fishing, fish processing and farming, fisheries conservation, production support services, scientific research and education [1], and therefore making management in the fishery industry more effective utilizing enabling digital technologies is particular topical now.

\footnotetext{
${ }^{*}$ Corresponding author: $\underline{\text { dubinina-nat } @ \text {,rambler.ru }}$
} 


\section{Materials and methods}

The methods of systems analysis, management, forecasting and decision theories are used in the study.

The theoretical framework for the study includes the research papers written by Russian and foreign authors on digitalization in management, fundamental research on the formation and development of integration structures, methodological backgrounds in management of fishery integration associations (IA), innovations and solutions for management of integration associations based on information systems and technologies.

The methodological framework for the study includes a systems approach to integration associations management, general scientific approaches to analysis and synthesis, methods and applications of IT-based IA management models, and graphic methods of analysis as well.

\section{The study on application of IT systems in fishery}

The studies indicate that, whatever the forms of integration in fishery, the evolution of integration processes implies an interconnection between several member companies, which are involved in different business activities in fishing, fish farming, similar service provision, processing and canning of inland and marine products and united by a common goal in an integrated process chain.

However, overlapping goals and interests of development and each participant's keenness to reach all this in time may lead to a conflict of interests within the IAs, because several independent management systems are being actually created [2].

Hence, in order to meet the strategic goals, retain and develop a competitive advantage, it's necessary to effectively organize the activities within the selected form of IA and create an appropriate IT management environment, which shall provide an opportunity to analyze the data and expedite the decision-making process.

Risks and business environmental uncertainty of economic entities impact the data acquisition, processing, assessment and the way data is represented as well. Thus, it becomes important, when adopting any IT technology, to appreciate the necessity for utilizing dedicated tools to operate it and then work out a necessary management solution based on it. The selected IT technologies should therefore be sensitive to the latest advances in theory and practice of new data conversion and identification to take a cost-effective decision.

So, this highlights principally the need to obtain a reliable data and manage the activity in real time. The identified issues can be solved now by using a wide range of information systems and technologies. But the practice of digitalization in fishery made it possible to identify a number of certain difficulties:

- Quality improvement of activities performed and a large number of information systems utilized within the IA refer to an increase in the volume of documentation and general data:

- single tool for obtaining and sharing data between the IA members is missing;

- lack of coordination in data communication between members in stages of life cycle of the activities being implemented;

- no instant access to the latest and relevant information.

The reasons for the loss of some data are as follows:

- data concentrated in different databases and storages;

- keeping a part of important information in the archives using paper based documents;

- no unified document marking system [3]. 


\section{Formation of unified management information system for fishery integration associations}

It is possible to resolve the issues hereinbefore explained by changing the approach to management digitalization, namely, creating a Unified Management Information System, where close interactions and strong interrelation of structural elements, that act as separate business processes within an integration association, shall be assured and maintained. And this system shall perform not only production functions, but also deal with the procurement, service, logistics, and be able to resolve organizational and legal issues, etc.

UMIS is a platform with integrated corporate information systems, that improve management efficiency through:

- data accumulation during the activity;

- enhancement in directions of information exchange between all IA members;

- completion of data transfer to information systems used by individual IA members;

- preparation of integrated quality solutions.

A unified information model will improve the efficiency for cooperation of all AI members, reduce issues with costs, time and risks referred to ongoing projects. Thanks to the implementation of a Unified Information System into the AI management, not only will the software product be changed, but the very approach to managing business structures will be changed.

The main purpose of UMIS is to provide all management levels of IA and member companies with complete and reliable information on the results of activities performed, research and costs, necessary to achieve all assigned production goals, carry out a financial and economic analysis, and put a strategic planning into practice [4].

Figure 1 illustrates a conceptual diagram of UMIS structure of fishery IA.

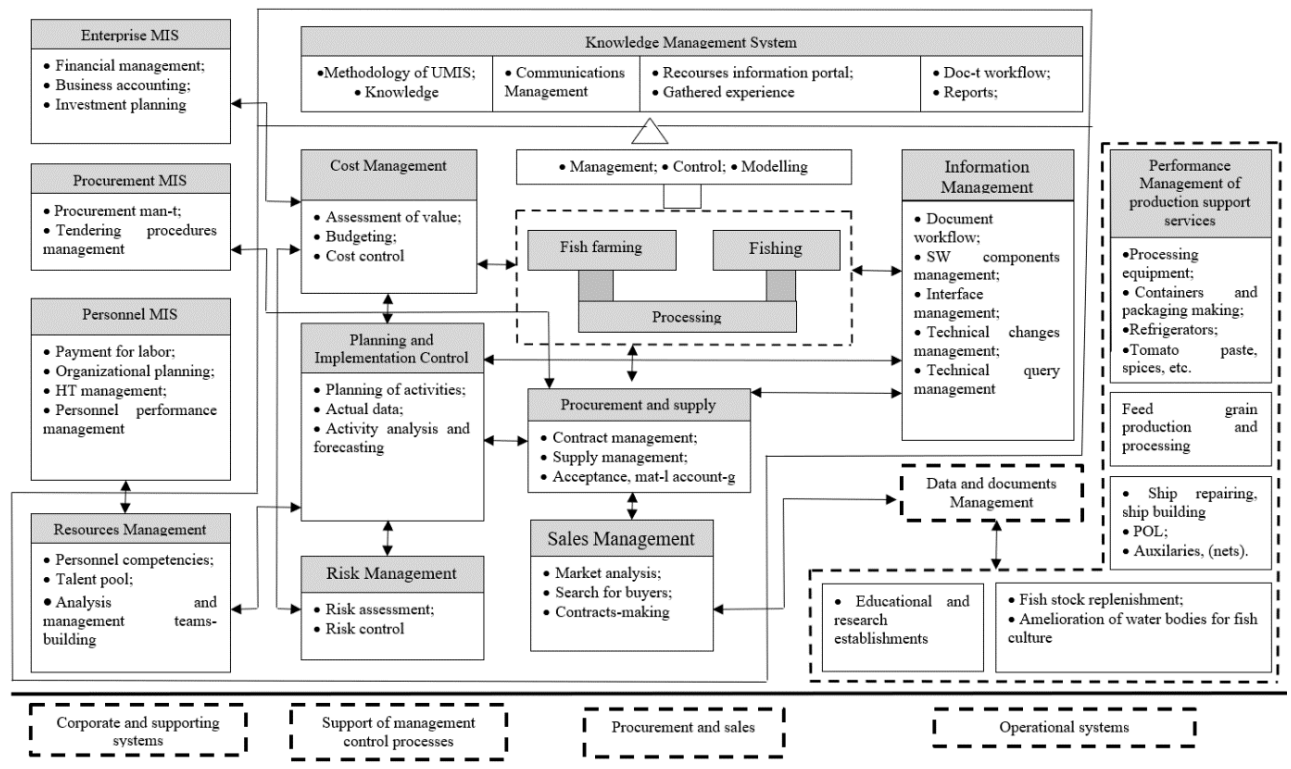

Fig. 1. A conceptual diagram of Unifies Management Information System structure of fishery integration association.

Whereas, the formation and implementation of UMIS shall ensure:

- creation of a support system for managerial decisions-making and no-delay resource management, providing transparency and controllability of business processes; 
- formation of a common information space within the management decision-making support system and operational resource management.

Considering that each built-in information system in UMIS has its own readings from many applications (fishing, fish farming, fish processing and canning, protection of fish stocks, scientific research, education), so then, there is a task to compare the available databases from each information system and arrange in a single «window» during their integration [5].

All analytical data of business structures are integrated in a UMIS by forming production data models, which facilitates the task to transfer the necessary data for all involved information systems. The formation of production data models will ensure the simplicity and transparency during data exchange between the information systems of member companies at all stages of the production life cycle [5].

This approach assures correct understanding and interpretation of information transmitted through data links:

-effectiveness of scaling the Information Management System. According to this principle, integration platform makes it possible to ensure entry additional data and its distribution around the business structures' facilities of IA members, due to the developed information systems;

- separation of data acquisition and transmission in each specific integrated information system. Each system involved is supplied with the necessary components to receive and transform the data provided by the integration platform;

- service orientation of the platform architecture. Each system must have access not only to the database, but also to the data of commercial and custom applications;

- the principle of security means that the data management system has an advanced mechanism to protect the transmitted data and is able to adapt to various architectural security systems of integrated information systems [6].

The following are the structural elements of the Unified Management Information System of the fishery integration association:

- corporate and supporting systems (Enterprise MIS, Procurement MIS, Personnel MIS, Resources management);

- support of management control processes (Cost Management, Planning and Implementation Control, Risk Management);

- knowledge management system (Recourses information portal, Communications Management, document workflow, reports, Methodology of UMIS, gathered experience);

- procurement and sales (procurement and supply Management, Sales Management);

- operational systems (Performance Management of production support services).

The UMIS implementation will arrange the relations between main (fishing, farming, processing) and auxiliary units (service, educational and research establishments), which are the part of a single production process within an integration association.

Utilizing UMIS in the fishery supports the production data exchange between the participants of integration process, without regard for the type of systems used.

The following classes of automation systems can be utilized simultaneously in the UMIS model, for example: ERP - Enterprise Resource Planning, Primavera Systems Spider Project, Open Plan, Project Scheduler Suite, Process Integration, which cover functions of planning, control, analysis, resource, stock and procurement management, risk management and document workflow [5].

Implementing UMIS to the fishery IA may call for modernization of the existing information servers by installing additional software. In addition, when implementing UMIS, it is necessary to establish a database and work out scenarios, and this is the reason why additional expenses for consulting and expert groups costs might be required. 
The proposed concept of UMIS for fishery IAs has a number of advantages and can help business:

- ensure transparency of initial information for all users, allowing the user do not have an issue with storing the data for its further search and retrieval;

- establish conditions for uniformity when interacting with, which is assured through a single virtual data source.

This approach provides an opportunity to assure:

- investment cycle management, pertaining to annual investment program, project structuring to specific facilities, calculation of expenditures in the context of individual facilities;

- material flow management (products and another goods) in the scope of application management, procurement management, inventory management, write-off management;

- management of the production facilities technical conditions: maintaining a single structure of production facilities, monitoring changes in the status of production facilities, record of fixed asserts utilization, equipment downtime accounting;

- contractual document management in terms of a unified structure of contractual documents, registration of all contractual documents in Unified Information System;

- preparation of reliable and current financial, tax and management reports to analyze the activity of IA and make a decision.

- harmonization of reference information and information on regulations, arrange a corporate management of reference data and communication with the corporate system of dictionaries and reference books, data exchange with another systems integrated into the Unified Information System;

- integration of logistics processes with business accounting and management one;

- activities results and effectiveness monitoring, calculation of profit and loss with the required details.

- standardization of accounting operations reflected in the System, regardless of the territorial distribution of business structures;

- feasibility of adaptable analytical reports based on the accumulation of intelligence in the System, received during the economic activities of IA business structures.

\section{Organizational structures of umis management}

Implementing UMIS to the fishery IA requires a formation of an appropriate organizational structure. The main task here involves the UMIS realization and development within a short time, with reasonable fundraising. In order to reduce time, the data shall be managed on the principals of centralization, i.e. there shall be introduced a centralized structure, where a maintenance of business processes unified model will be a basis for UMIS implementation.

However, implementing UMIS within IA also calls for a compromise: on the one hand, it is necessary to satisfy the requirements of business, on the other hand, implementation and selection of UMIS must be agreed upon all IA participants.

A unified standard model of business processes should be the most important component here, which allows, at the same time, to consider the specific activity features of IA member companies.

To comply with and implement this requirements, it is necessary to grant the corporate status to the management bodies. The management layout shall assure high efficiency in coordination of requirements for UMIS from all parties involved, and sufficient representativity for decision making as well.

For improvements and optimization, the management system shall be focused on the key activities of IA and based on the principle of specialization. 
As part of UMIS realization, to apply a unified model of business processes, it is also necessary to make structural changes: centralize the accounting and taxes services, logistics and HR. Such an approach will enable an effective use of resources, involved in the UMIS creation and development, and preserve continuity of personnel when implementing UMIS [7].

On the ground of principles of management, it is necessary to classify organizational elements. either to an independent and additional organizational unit, or to organizational units that exist in IA organizational structure.

To complete the tasks, a creation of Monitoring Centre is proposed. General strategic management, control over the progress of UMIS implementation is performed by the Head of UMIS development program within the IA. The administrator manages and coordinates the stages of planning, accounting and reporting during the implementation phases (Figure 2).

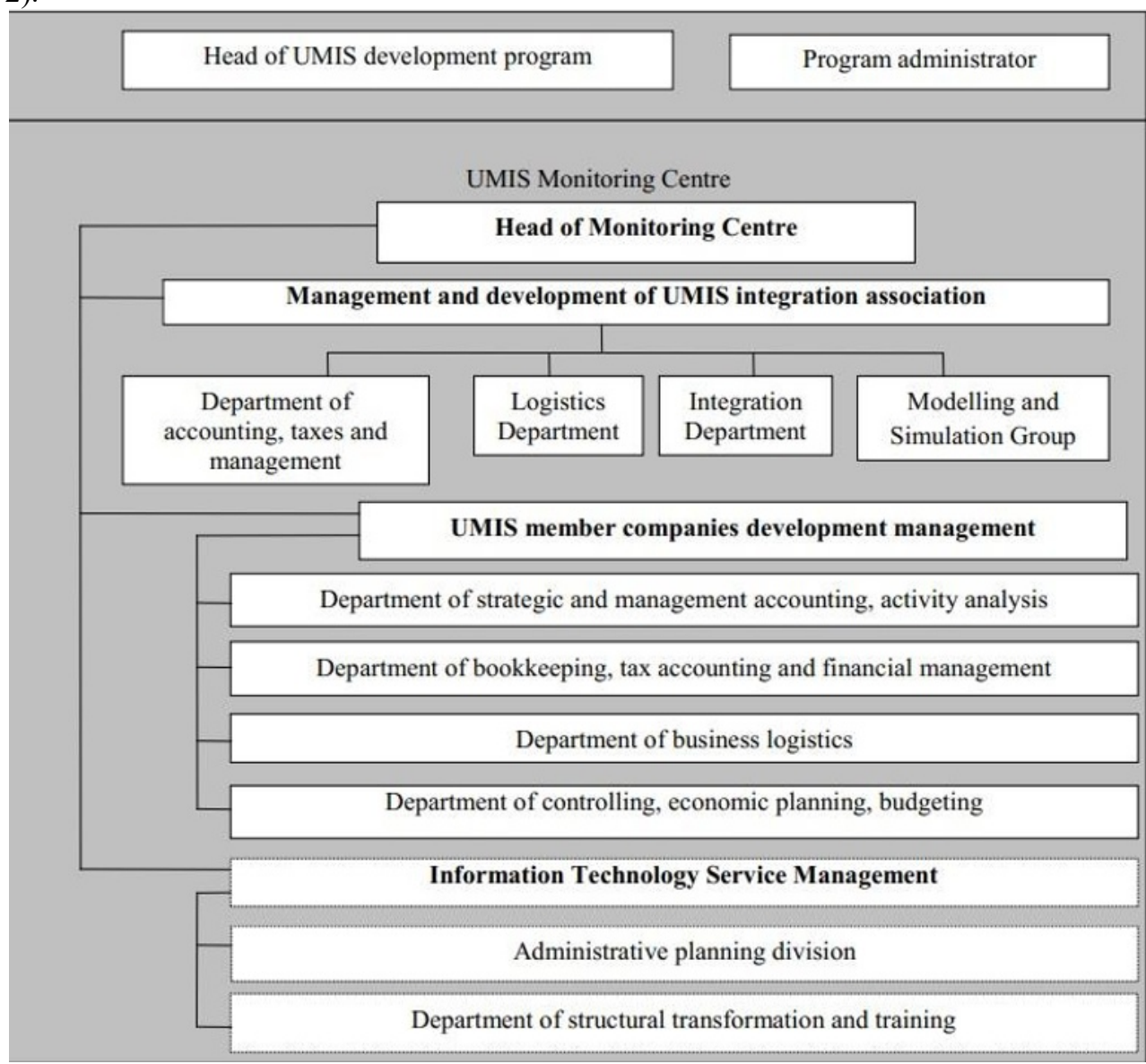

Fig. 2. Organizational structure for management and development of UMIS.

An ability to effectively coordinate individual related operations of a general functional purpose can be described as the main advantage of organizational structure for UMIS management.

It should be noted, that the proposed version of organizational structure for UMIS management and development is to arrange a horizontal integration of production, including several levels of management, which is currently important for the Russian fishery. 
An integration of several levels of management results in end-to-end management, where workers at fishing areas, who really know how fishing grounds work, as well as personnel, participating in fish farming, processing and canning or auxiliary or service facilities are involved in it

\section{Conclusion}

Thus, the realization of Unified Management Information System provides an information support for main and auxiliary units of industry, effective decision-making, opportunity to assess the results of IA production activities as a whole, its business structures and individual divisions, and services as well.

Utilizing a Unified Management Information System for integration associations in fishery will cause a reduction of risks of false solutions and wrong management decisions and facilitate greater economic effect.

\section{References}

1. Dubinina N A, Karlina E P, Michurina O Yu 2018 Bulletin of Perm University. Series: Economics 13(1) 106

2. Korneiko O V 2015 Bulletin of Perm University. Series: Economics 1(24) 46

3. Chertina E V, Kvyatkovskaya I Yu, Khomenko T V 2017 Bulletin of Astrakhan State Technical University Series: Management, Programming and Computer Software 2117

4. Shinkaretskaya G G and Berman A M 2019 Education and Law 7260

5. Kovalchuk V V and Seneckaya L B 2010 Bulletin of the Murmansk State Technical University 13(1) 136

6. Ereshko F I, Medennikov V I, Bogatyreva L V 2019 12th International Conference "Management of the development of large-scale systems" 220

7. Sukhanov V 2010 Rational enterprise management 13 